Jurnal Elektro Telekomunikasi Terapan Desember 2020

\title{
APLIKASI PEMBACAAN OBJEK UNTUK IDENTIFIKASI BUKU BERBASIS PENGOLAHAN CITRA
}

\section{APPLICATION OF OBJECT RECITATION FOR BOOK IDENTIFICATION BASED ON IMAGE PROCESSING}

\author{
Muhammad Obi Nugraha $^{1}$, Suci Aulia ${ }^{2}$, Atik Novianti $^{3}$ \\ 1,2,3Program Studi D3 Teknologi Telekomunikasi, Fakultas Ilmu Terapan, Universitas Telkom \\ 10bi.nugraha@gmail.com, ${ }^{2}$ suciaulia@ telkomuniversity.ac.id, ${ }^{3}$ atiknovianti@telkomuniversity.ac.id
}

\begin{abstract}
Abstrak
Merujuk dari Kamus Besar Bahasa Indonesia (KBBI), perpustakaan dapat diartikan sebagai tempat perawatan dan pemanfaatan buku dan koleksi sejenis yang berada di sana. Beberapa koleksi yang ada di perpustakaan bisa dipinjam dan dibawa pulang dalam durasi waktu tertentu. Seiring perkembangan zaman, sudah banyak perpustakaan yang memanfaatkan teknologi untuk mengidentifikasi buku terutama dalam proses peminjaman buku. Beberapa teknologi yang sering digunakan misalkan barcode dan QR code. Masing-masing teknologi memiliki kelebihan dan kekurangan, kami mencoba untuk memanfaatkan proses pengolahan citra untuk identifikasi buku. Konsep yang diajukan adalah pembuatan aplikasi untuk mengidentifikasi citra objek berdasarkan bentuk, warna, dan angka sebagai identitas dari sebuah buku. Informasi yang akan ditampilkan telah tersimpan pada database. Citra objek pada bagian depan buku diambil menggunakan kamera, setelah itu secara otomatis sistem akan mengidentifikasi hasil penangkapan kamera dan menampilkan informasi buku sesuai dengan yang ada di database. Pembuatan aplikasi menggunakan software Matlab. Berdasarkan hasil pengujian, jarak ideal antara buku dengan kamera adalah $5 \mathrm{~cm}$ dengan minimal intensitas cahaya 40 lx dan resolusi citra $302 \times 170$ px. Rata-rata waktu yang dibutuhkan mulai kamera mengambil citra sampai aplikasi menampilkan informasi buku adalah 0.56 detik.
\end{abstract}

Kata kunci : bentuk, warna, angka, pengolahan citra, Matlab

\begin{abstract}
Referring to Kamus Besar Bahasa Indonesia (KBBI), the library can be defined as a place for the care and use of books and similar collections that are there. Some collections in the library can be borrowed and brought home within a certain duration. Along with the times, many libraries have used technology to identify books, especially in the process of borrowing books. Some of the technologies that are often used include barcodes and QR codes. Each technology has advantages and disadvantages, we try to take advantage of the image processing process for book identification. The concept proposed is making an application to identify object images based on shapes, colors, and numbers as the identity of a book. The information to be displayed is stored in the database. The image of the object on the front of the book is taken using the camera, after which the system will automatically identify the results of the camera's capture and display the book information according to what is in the database. Application development using Matlab software. Based on the test results, the ideal distance between the object image and the camera is $5 \mathrm{~cm}$ with a minimum light intensity of $40 \mathrm{~lx}$ and an image resolution of 302x170 px. The average time taken from the camera to take an image until the application displays book information is 0.56 seconds.
\end{abstract}

Keywords: shape, color, number, image processing, Matlab

\section{PENDAHULUAN}

Merujuk dari Kamus Besar Bahasa Indonesia (KBBI), perpustakaan dapat diartikan sebagai tempat perawatan dan pemanfaatan buku dan koleksi sejenis yang berada di sana [1]. Beberapa 
koleksi yang ada di perpustakaan bisa dipinjam dan dibawa pulang dalam durasi waktu tertentu. Proses peminjaman koleksi perpustakaan sangat bervariasi, mulai dari yang pelayanan secara mandiri ataupun masih dibantu operator. Seiring perkembangan zaman, sudah banyak perpustakaan yang memanfaatkan teknologi untuk mengidentifikasi buku terutama dalam proses peminjaman buku. Beberapa teknologi yang sering digunakan misalkan barcode dan QR code [2]-[4]. Masing-masing teknologi memiliki kelebihan dan kekurangan, kami mencoba memanfaatkan proses pengolahan citra untuk identifikasi buku.

Pada penelitian sebelumnya dalam judul "Perancangan Aplikasi Pembaca Warna dan Bentuk Berbasis Pengolahan Citra Untuk Daftar Katalog Perpustakaan", telah dibuat sistem identifikasi katalog perpustakaan berbasis pengolahan citra [5]. Kekurangan dari penelitian tersebut adalah jumlah variasi objek yang dapat ditampilkan sedikit. Hal tersebut dikarenakan aplikasi hanya dapat membaca tiga warna pada tiga bentuk yang berbeda, sehingga maksimal hanya ada sembilan kemungkinan yang dapat terjadi. Sedangkan di perpustakaan tentunya membutuhkan lebih dari sembilan variasi buku. Oleh karena itu, pada tulisan ini akan dijelaskan konsep pengolahan citra agar dapat membaca lebih banyak variasi buku. Data dari masing-masing buku direpresentasikan oleh sebuah objek yang terdiri dari bentuk, warna, dan angka. Bentuk yang digunakan terdiri dari segitiga, lingkaran, dan persegi. Identifikasi warna meliputi warna dasar yaitu Red, Green, Blue (RGB). Untuk angka meliputi angka 0 sampai dengan 9. Sehingga dari variasi tersebut maka aplikasi dapat menampilkan sembilan puluh kemungkinan data buku, lebih banyak dibandingkan penelitian sebelumnya.

Konsep yang diajukan adalah pembuatan aplikasi untuk mengidentifikasi citra objek berdasarkan bentuk, warna, dan angka sebagai identitas dari sebuah buku. Informasi yang akan ditampilkan telah tersimpan pada database. Citra objek pada bagian depan buku diambil menggunakan kamera, setelah itu secara otomatis sistem akan mengidentifikasi hasil penangkapan kamera dan menampilkan informasi buku sesuai dengan yang ada di database. Identitas buku yang ditampilkan meliputi jenis buku, judul, penulis, dan jumlah halaman. Pembuatan aplikasi menggunakan software Matlab.

Pembuatan aplikasi menggunakan software Matlab.

\section{RANCANGAN SISTEM}

\subsection{Gambaran Umum Sistem}

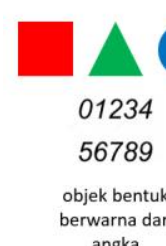

angka

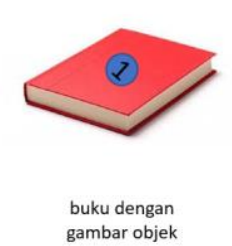

gambar objek
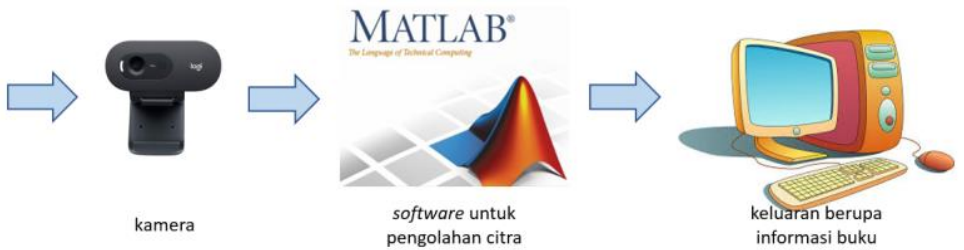

Gambar 1. Sistem Identifikasi Buku Berdasarkan Warna, Bentuk, dan Angka

Gambar 1 menunjukkan gambaran umum untuk proses identifikasi buku berdasarkan warna, bentuk, dan angka (yang selanjutnya disebut objek), dimana masing-masing buku akan terpasang hasil cetakan objek yang berbeda-beda. Variasi warna yang digunakan meliputi merah, hijau, dan biru, kemudian variasi bentuk terdiri dari kotak, segitiga, dan lingkaran, sedangkan untuk variasi angka ialah 0 sampai 9. Informasi tentang buku yang terpasang hasil cetakan objek telah dimasukan database sebelumnya. Pengambilan citra objek pada buku menggunakan kamera yang selanjutnya 
akan melalui beberapa proses pengolahan citra untuk menentukan bentuk, warna, dan angka apa yang teridentifikasi. Bentuk, warna, dan angka yang terbaca akan dicocokkan dengan data yang terdapat pada database, kemudian keluaran dari aplikasi tersebut adalah informasi buku yang sesuai.

\subsection{Alur Identifikasi Objek}

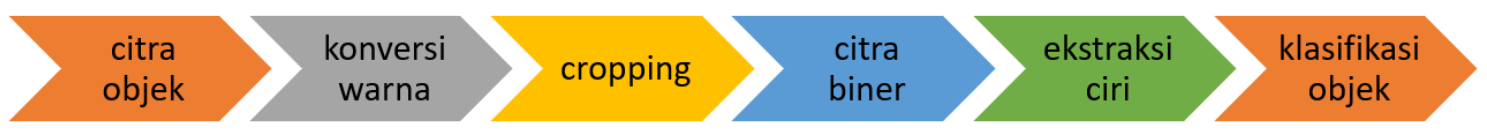

Gambar 2. Proses Pengenalan Objek Sistem Identifikasi Buku Berdasarkan Warna, Bentuk, dan Angka

Pada tahap identifikasi objek terdapat beberapa proses pengolahan citra yang dilakukan. Masukan dari pengolahan citra adalah citra objek yang terpasang pada buku, sedangkan keluaran berupa klasifikasi objek yang dapat dicocokkan dengan data pada database. Alur identifikasi objek ditunjukkan seperti Gambar 2. Terdapat pre-processing yang terdiri dari konversi warna ke greyscale, cropping, dan diubah menjadi citra biner, dilanjutkan dengan ekstraksi ciri, serta yang terakhir adalah klasifikasi objek. Citra objek yang merupakan citra berwarna (RGB) akan dikonversi menjadi citra grayscale yang memiliki gradasi warna dari hitam sampai putih. Pendekatan untuk konversi citra RGB menjadi citra grayscale dapat menggunakan Persamaan (1), yang belum umum digunakan untuk aplikasi machine vision karena masing-masing layer $(\mathrm{R}, \mathrm{G}$, dan $\mathrm{B})$ memiliki daya spektral yang berbeda. Oleh sebab itu digunakan metode National Television Standards Committee (NTSC) yang telah diterima sebagai pendekatan umum seperti ditunjukkan pada Persamaan (2) [6].

$$
\begin{gathered}
I=\frac{R+G+B}{3} \\
I=0.299 * R+0.587 * G+0.114 * B
\end{gathered}
$$

Proses selanjutnya adalah menghapus area yang tidak diinginkan (cropping) agar tetap fokus pada konten penting citra [7]. Setelah itu, agar citra objek dapat dipisahkan dari latar belakangnya maka perlu diubah menjadi citra biner. Beberapa keunggulan citra biner antara lain adalah waktu komputasi yang relatif cepat karena dapat menggunakan operasi logika, serta kebutuhan memori yang sedikit untuk tiap pikselnya [8]. Masuk pada bagian ekstraksi ciri yang bertujuan untuk mengekstrak informasi pada citra objek sehingga dapat digunakan sebagai acuan pembeda antar objek. Penentuan bentuk citra objek menggunakan nilai persentase luas yang merepresentasikan jumlah piksel penyusun objek tersebut. Aplikasi akan mencirikan bentuk persegi saat persentase luas lebih besar dari 85, bentuk lingkaran saat persentase luas lebih besar dari 65, dan selain itu bentuk segitiga.

Pencirian merah, hijau, atau biru dilakukan dengan cara segmentasi citra objek menjadi beberapa area bermakna yang tidak saling tumpang tindih (overlapping) [9]. Citra objek akan dibagi menjadi beberapa layer penyusun warna dasar yaitu merah, hijau, dan biru. Tiap layer akan dihitung rata-rata dari nilai yang terdapat pada masing-masing piksel. Algoritma yang digunakan untuk mencirikan warna merah, hijau dan biru seperti pada Gambar 3. Terakhir adalah ekstraksi ciri pada angka dengan menggunakan template matching, yakni cara yang digunakan dalam pengolahan citra untuk mendapatkan bagian dari suatu citra yang cocok dengan template yang telah disediakan sebelumnya [10]. 


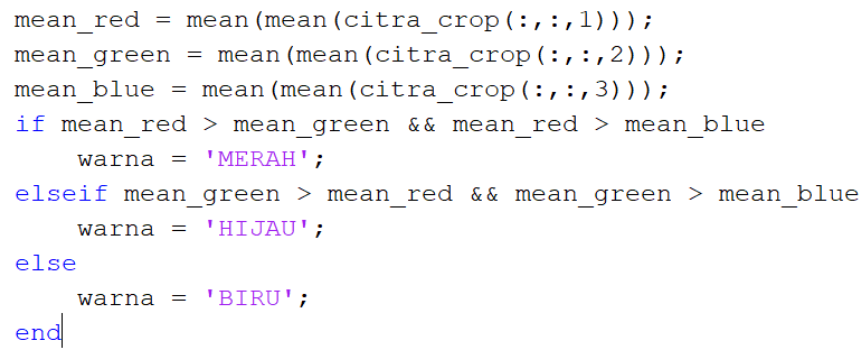

Gambar 3. Algoritma Ekstraksi Warna

\subsection{Pembuatan Tampilan Aplikasi dan Database}

Pembuatan aplikasi pembacaan objek untuk identifikasi buku menggunakan software Matlab, termasuk untuk pembuatan tampilan aplikasi memanfaatkan Graphical User Interface (GUI) Matlab. Desain tampilan aplikasi seperti ditunjukkan pada Gambar 4. Selain menampilkan citra objek sebagai masukan dan informasi buku sebagai keluaran, aplikasi juga menampilkan keluaran proses deteksi bentuk dan warna, serta deteksi angka. Sedangkan database untuk menampung data buku yang akan diidentifikasi menggunakan software Excel seperti yang tersaji pada Gambar 5.

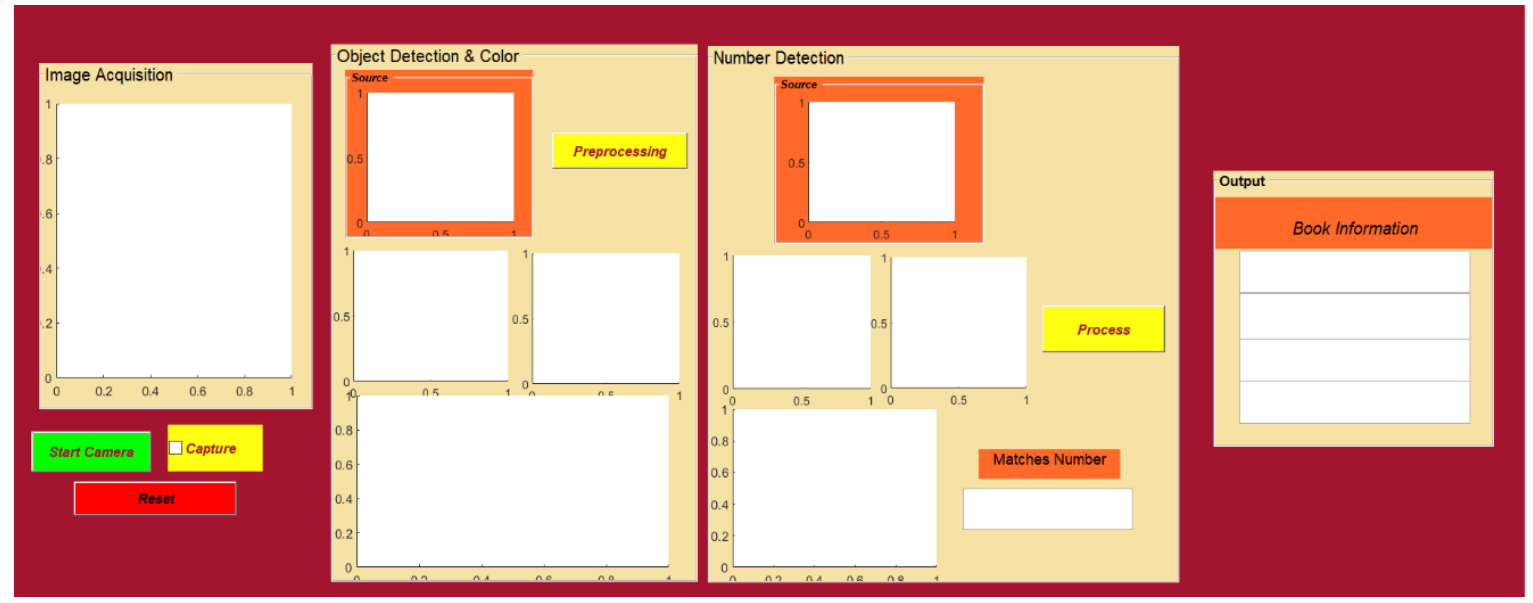

Gambar 4. Desain Tampilan Aplikasi

\begin{tabular}{|c|c|c|c|c|c|c|}
\hline 4 & A & B & c & D & E & $\mathrm{F}$ \\
\hline 1[ & KOTAK BIRU & NOVEL & 1 & BENEATH THE SAPPIHIRE EYES & J. Miles & jumlah halaman : 298 \\
\hline 2 & KOTAK BIRU & NOVEL & 2 & MINE & ATIKA & jumlah halaman : 333 \\
\hline 3 & KOTAK BIRU & NOVEL & 3 & THE FAULT IN OUR STAR & Jhon Green & jumlah halaman : 333 \\
\hline 4 & KOTAK MERAH & NOVEL & 1 & DIVERGENT & Veronica Roth & jumlah halaman : 487 \\
\hline 5 & KOTAK MERAH & NOVEL & 2 & INSURGENT & Veronica Roth & jumlah halaman : 525 \\
\hline 6 & KOTAK MERAH & NOVEL & 3 & JIKA AKU TETAP DISINI & Gayle Forman & jumlah halaman : 210 \\
\hline 7 & KOTAK HIJAU & NOVEL & 1 & JUST ONE DAY & Gayle Forman & jumlah halaman : 404 \\
\hline 8 & KOTAK HIJAU & NOVEL & 2 & SANG PEMIMPI & Andrea Hirata & jumlah halaman : 292 \\
\hline 9 & KOTAK HIJAU & NOVEL & 3 & NEGERI 5 MENARA & Ahmad Fuadi & jumlah halaman : 444 \\
\hline 10 & KOTAK BIRU & NOVEL & 10 & KETIKA CINTA BERTASBIH & Habiburrahman El Shirazy & jumlah halaman : 417 \\
\hline 11 & SEGITIGA HIJAU & BIOGRAFI & 1 & BECOMING & Michelle Obama & jumlah halaman : 631 \\
\hline 12 & SEGITIGA HIJAU & BIOGRAFI & 2 & STEVE JOBS & Walter Isaacson & jumlah halaman : 259 \\
\hline 13 & SEGITIGA HIJAU & BIOGRAFI & 3 & JUST KIDS & Patti Smith & jumlah halaman : 321 \\
\hline 14 & SEGITIGA MERAH & BIOGRAFI & 1 & EDUCATED & Tara Wastover & jumlah halaman : 431 \\
\hline 15 & SEGITIGA MERAH & BIOGRAFI & 2 & I KNOW WHY THE CAGED BIRD SINGS & Maya Angelou & jumlah halaman : 259 \\
\hline 16 & SEGITIGA MERAH & BIOGRAFI & 3 & MY THOUGHST EXACTLY & Lily Allen & jumlah halaman : 343 \\
\hline 17 & SEGITIGA BIRU & BIOGRAFI & 1 & CHURCHILL: A LIFE & Martin Gilbert & jumlah halaman : 1111 \\
\hline 18 & SEGITIGA BIRU & BIOGRAFI & 2 & WILD SWANS: THREE DAUGTHERS OF CHINA & Jung Chang & jumlah halaman : 530 \\
\hline 19 & SEGITIGA BIRU & BIOGRAFI & 3 & BIOGRAFI GUS DUR & Greg Barton & jumlah halaman : 439 \\
\hline 20 & SEGITIGA MERAH & BIOGRAFI & 10 & JAIS DARGA NAMAKU & Ahda Imran & jumlah halaman : 310 \\
\hline 21 & LINGKARAN BIRU & SEJARAH & 1 & SEJARAH TUHAN & Karen Amstrong & jumlah halaman : 460 \\
\hline 22 & LINGKARAN BIRU & SEJARAH & 2 & A HISTORY OF THE ARAB PEOPLE & Albert Hourani \& Malise & jumlah halaman : 576 \\
\hline 23 & LINGKARAN BIRU & SEJARAH & 3 & API SEJARAH 1 & Ahmad Mansyur S & jumlah halaman : 485 \\
\hline
\end{tabular}

Gambar 5. Tampilan Database Aplikasi Identifikasi Buku Berdasarkan Warna, Bentuk, dan Angka 


\section{HASIL DAN PENGUJIAN SISTEM}

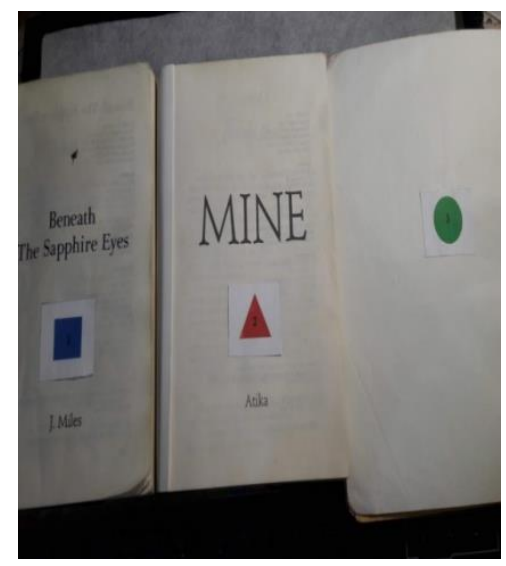

Gambar 6. Contoh Citra Objek dan Pemasangan di Buku

Sebelum pengujian sistem maka yang perlu dilakukan adalah mempersiapkan citra objek yang diskenariokan terpasang pada masing-masing buku untuk diidentifikasi. Citra objek terdiri dari satu angka yang dicetak menggunakan font Times New Roman ukuran 12, satu bentuk dengan ukuran disesuaikan, dan satu warna. Saat pengambilan citra, agar proses identifikasi dapat berjalan dengan baik maka citra objek harus memiliki background putih. Contoh citra objek dan pemasangan di buku ditampilkan pada Gambar 6. Seperti telah disampaikan pada bagian sebelumnya, selain keluaran berupa informasi buku, aplikasi pembacaan objek juga menampilkan proses deteksi bentuk dan warna, serta deteksi angka. Gambar 7 pada bagian deteksi objek dan warna terdapat proses konversi warna dari citra objek asli diubah menjadi citra grayscale dan citra biner (black and white). Selanjutnya ada proses cropping dan segmentasi untuk identifikasi bentuk dan warna. Sedangkan untuk identifikasi angka juga terdapat proses perubahan warna dari citra asli hingga closing untuk memperhalus citra. Saat hasil identifikasi bentuk, warna, dan angka terdapat pada database, maka aplikasi akan menampilkan informasi buku sesuai dengan hasil pembacaan objek. Setelah aplikasi selesai dibuat, akan dilakukan pengujian untuk menvalidasi kehandalan sistem.

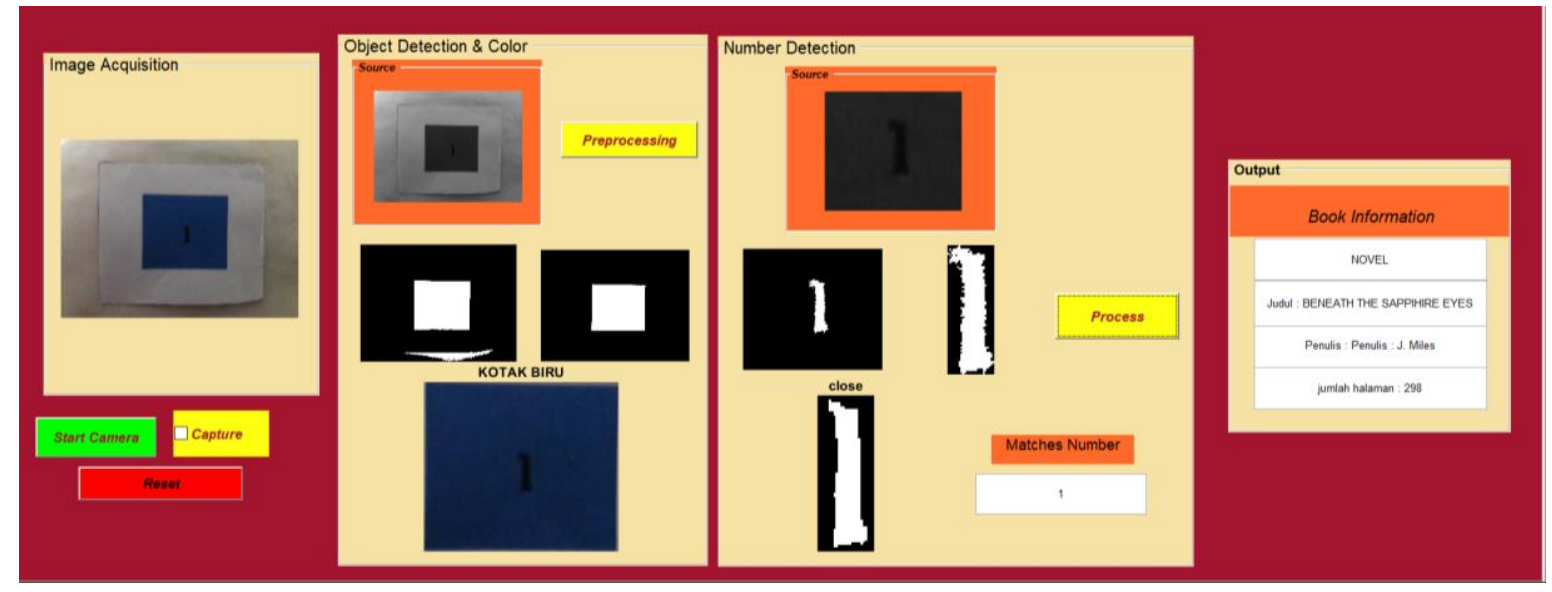

Gambar 7. Tampilan Aplikasi Identifikasi Buku Berdasarkan Warna, Bentuk, dan Angka

\subsection{Pengujian Jarak Kamera Terhadap Buku}

Bertujuan mengetahui jarak ideal pengambilan citra objek pada buku dengan hasil keluaran yang benar. Pengujian dilakukan dengan cara menvariasikan jarak kamera terhadap buku mulai dari 
Jurnal Elektro Telekomunikasi Terapan Desember 2020

$1 \mathrm{~cm}$ hingga $10 \mathrm{~cm}$, dimana kamera berada tepat di depan citra objek. Masing-masing jarak diuji untuk tiga variasi bentuk dan tiga variasi angka. Pengambilan data untuk masing-masing kondisi dilakukan sebanyak sepuluh kali. Data pengujian seperti dituliskan pada Tabel 1.

Tabel 1. Data Pengujian Jarak Kamera Terhadap Buku

\begin{tabular}{|c|c|c|c|c|c|}
\hline Jarak & Bentuk & Angka & $\begin{array}{c}\text { Total } \\
\text { Pengujian }\end{array}$ & $\begin{array}{c}\text { Total } \\
\text { Keberhasilan }\end{array}$ & $\begin{array}{c}\text { Rata-rata } \\
\text { Akurasi }\end{array}$ \\
\hline \multirow{3}{*}{$1 \mathrm{~cm}$} & Segitiga & $1-3$ & 30 & 0 & \multirow{3}{*}{$0 \%$} \\
\hline & Persegi & $1-3$ & 30 & 0 & \\
\hline & Lingkaran & $1-3$ & 30 & 0 & \\
\hline \multirow{3}{*}{$2 \mathrm{~cm}$} & Segitiga & $1-3$ & 30 & 0 & \multirow{3}{*}{$0 \%$} \\
\hline & Persegi & $1-3$ & 30 & 0 & \\
\hline & Lingkaran & $1-3$ & 30 & 0 & \\
\hline \multirow{3}{*}{$3 \mathrm{~cm}$} & Segitiga & $1-3$ & 30 & 0 & \multirow{3}{*}{$0 \%$} \\
\hline & Persegi & $1-3$ & 30 & 0 & \\
\hline & Lingkaran & $1-3$ & 30 & 0 & \\
\hline \multirow{3}{*}{$4 \mathrm{~cm}$} & Segitiga & $1-3$ & 30 & 0 & \multirow{3}{*}{$0 \%$} \\
\hline & Persegi & $1-3$ & 30 & 0 & \\
\hline & Lingkaran & $1-3$ & 30 & 0 & \\
\hline \multirow{3}{*}{$5 \mathrm{~cm}$} & Segitiga & $1-3$ & 30 & 30 & \multirow{3}{*}{$100 \%$} \\
\hline & Persegi & $1-3$ & 30 & 30 & \\
\hline & Lingkaran & $1-3$ & 30 & 30 & \\
\hline \multirow{3}{*}{$6 \mathrm{~cm}$} & Segitiga & $1-3$ & 30 & 30 & \multirow{3}{*}{$99.33 \%$} \\
\hline & Persegi & $1-3$ & 30 & 28 & \\
\hline & Lingkaran & $1-3$ & 30 & 30 & \\
\hline \multirow{3}{*}{$7 \mathrm{~cm}$} & Segitiga & $1-3$ & 30 & 28 & \multirow{3}{*}{$98 \%$} \\
\hline & Persegi & $1-3$ & 30 & 28 & \\
\hline & Lingkaran & $1-3$ & 30 & 28 & \\
\hline \multirow{3}{*}{$8 \mathrm{~cm}$} & Segitiga & $1-3$ & 30 & 0 & \multirow{3}{*}{$0 \%$} \\
\hline & Persegi & $1-3$ & 30 & 0 & \\
\hline & Lingkaran & $1-3$ & 30 & 0 & \\
\hline \multirow{3}{*}{$9 \mathrm{~cm}$} & Segitiga & $1-3$ & 30 & 0 & \multirow{3}{*}{$0 \%$} \\
\hline & Persegi & $1-3$ & 30 & 0 & \\
\hline & Lingkaran & $1-3$ & 30 & 0 & \\
\hline \multirow{3}{*}{$10 \mathrm{~cm}$} & Segitiga & $1-3$ & 30 & 0 & \multirow{3}{*}{$0 \%$} \\
\hline & Persegi & $1-3$ & 30 & 0 & \\
\hline & Lingkaran & $1-3$ & 30 & 0 & \\
\hline
\end{tabular}

Tabel 1 menunjukkan bahwa pada jarak $1 \mathrm{~cm}$ sampai $4 \mathrm{~cm}$ sistem tidak dapat mengidentifikasi citra objek sama sekali karena jarak buku dan kamera terlalu dekat, sehingga informasi buku tidak dapat ditampilkan. Pada jarak $5 \mathrm{~cm}$ hingga $7 \mathrm{~cm}$ sistem dapat mengidentifikasi citra objek dan menampilkan informasi buku yang sesuai, dimana hasil maksimal diperoleh pada jarak $5 \mathrm{~cm}$ dengan rata-rata akurasi $100 \%$. Saat buku dan kamera $8 \mathrm{~cm}$ ke atas maka sistem juga tidak dapat mengidentifikasi citra objek karena jarak yang terlalu jauh.

\subsection{Pengujian Kondisi Cahaya}

Pengujian dengan tujuan mengetahui pengaruh kondisi cahaya terhadap performansi sistem dalam mengidentifikasi citra objek dan menampilkan informasi buku yang sesuai. Pengambilan data dilakukan dengan cara menvariasikan intensitas cahaya dalam ruang pengujian yang diukur 
menggunakan lux meter, dimana kamera berada di depan citra objek dengan jarak $5 \mathrm{~cm}$. Pada masing-masing intensitas cahaya diuji tiga variasi bentuk dengan tiga variasi warna dan tiga variasi angka sebanyak sepuluh kali. Berdasarkan data pengujian yang disajikan pada Tabel 2 diketahui bahwa kondisi cahaya mempengaruhi performansi untuk identifikasi citra objek. Sistem dapat mendeteksi citra objek dengan benar dan menampilkan informasi buku yang sesuai selama masih ada cahaya, namun hasil terbaik untuk proses identifikasi ditunjukkan saat intensitas cahaya di atas $401 \mathrm{x}$.

Tabel 2. Data Pengujian Kondisi Cahaya

\begin{tabular}{|c|c|c|c|}
\hline $\begin{array}{c}\text { Kondisi Cahaya Saat } \\
\text { Pengujian }\end{array}$ & $\begin{array}{c}\text { Total } \\
\text { Pengujian }\end{array}$ & $\begin{array}{c}\text { Total } \\
\text { Keberhasilan }\end{array}$ & Akurasi \\
\hline & 90 & 84 & $94 \%$ \\
\hline & 90 & 88 & $98 \%$ \\
\hline & 90 & 90 & $100 \%$ \\
\hline & & & \\
\hline & 90 & 90 & $100 \%$ \\
\hline & & & \\
\hline & & & \\
\hline
\end{tabular}




\subsection{Pengujian Waktu untuk Identifikasi Buku}

Tabel 3. Data Pengujian Waktu untuk Identifikasi Buku

\begin{tabular}{|c|c|c|c|c|}
\hline No & Warna & Bentuk & Angka & $\begin{array}{c}\text { Waktu Proses } \\
\text { (detik) }\end{array}$ \\
\hline 1 & \multirow{3}{*}{ Merah } & Segitiga & $1-3$ & 0.5 \\
\hline 2 & & Persegi & $1-3$ & 0.53 \\
\hline 3 & & Lingkaran & $1-3$ & 0.55 \\
\hline 4 & \multirow{3}{*}{ Biru } & Segitiga & $1-3$ & 0.58 \\
\hline 5 & & Persegi & $1-3$ & 0.91 \\
\hline 6 & & Lingkaran & $1-3$ & 0.49 \\
\hline 7 & \multirow{3}{*}{ Hijau } & Segitiga & $1-3$ & 0.53 \\
\hline 8 & & Persegi & $1-3$ & 0.50 \\
\hline 9 & & Lingkaran & $1-3$ & 0.52 \\
\hline \multicolumn{4}{|c|}{ Rata-rata waktu proses identifikasi } & 0.56 detik \\
\hline
\end{tabular}

Pengujian bertujuan untuk memperoleh rata-rata waktu sistem untuk menampilkan informasi buku yang sesuai berdasarkan hasil identifikasi citra objek. Proses pengujian dilakukan dengan menvariasikan warna, bentuk, dan angka pada jarak $5 \mathrm{~cm}$ dan intensitas cahaya 40 lx. Perhitungan waktu dimulai saat sistem mengambil citra hingga informasi buku ditampilkan. Tabel 3 menunjukkan bahwa rata-rata waktu yang dibutuhkan sistem untuk mengidentifikasi buku adalah 0.56 detik.

\subsection{Pengujian Kehandalan Terhadap Noise}

Tujuan dari pengujian adalah mengetahui kehandalan sistem untuk mengidentifikasi buku saat pada citra objek terdapat noise alami. Noise alami yang dimaksud adalah gangguan yang biasa terjadi pada buku, bukan gangguan buatan yang ditambahkan pada citra objek (misalkan salt and pepper noise). Noise yang diuji meliputi terdapat cairan pada citra objek, terdapat robekan pada citra objek, dan terdapat lipatan pada citra objek. Pengambilan data dilakukan dengan menggunakan jarak dan intensitas cahaya yang ideal sesuai pengujian sebelumnya yakni $5 \mathrm{~cm}$ dan $40 \mathrm{~lx}$. Hasil yang ditampilkan oleh Tabel 4 menunjukkan bahwa sistem belum dapat mengidentifikasi buku yang citra objeknya memiliki noise seperti yang disebutkan sebelumnya.

Tabel 4. Data Pengujian Kehandalan Terhadap Noise

\begin{tabular}{|c|c|c|c|c|c|}
\hline Noise & Citra Objek & $\begin{array}{c}\text { Identifikasi Bentuk dan } \\
\text { Warna }\end{array}$ & Identifikasi Angka & Hasil \\
\hline $\begin{array}{c}\text { Terdapat } \\
\text { cairan } \\
\text { pada citra }\end{array}$ & Image Acquistion & & & & Gagal \\
\hline
\end{tabular}




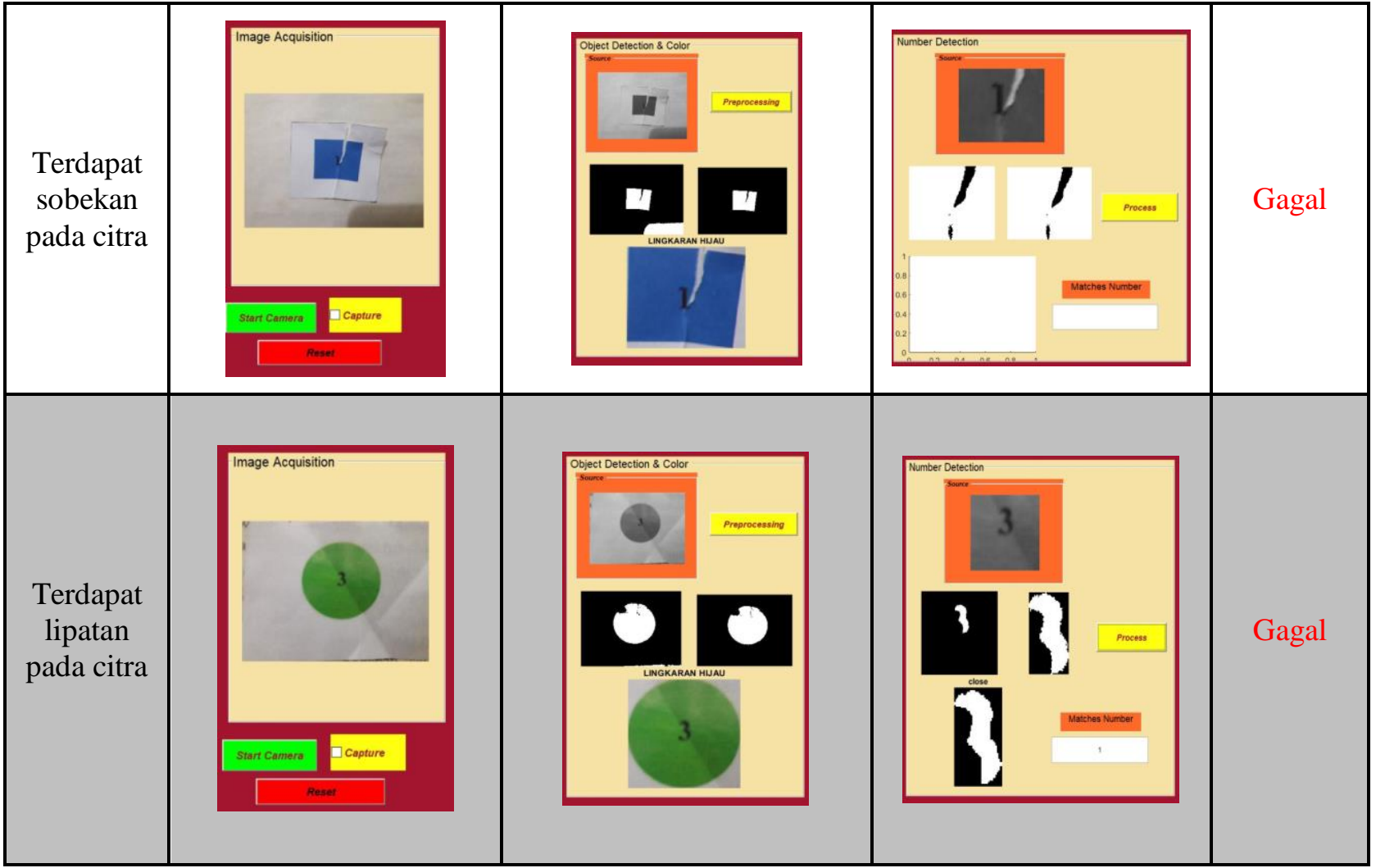

\subsection{Pengujian Tingkat Resolusi Citra}

Bertujuan mengetahui batas minimal resolusi citra objek yang dapat diidentifikasi sistem. Sesuai data pengujian yang disajikan pada Tabel 5, diketahui bahwa sistem dapat melakukan proses identifikasi dengan benar saat citra objek memiliki resolusi minimal 302x170 px. Pada resolusi citra di bawah 302x170 px, sistem gagal melakukan proses identifikasi dikarenakan ukuran piksel tidak memenuhi. Resolusi tersebut merepresentasikan ukuran piksel pada citra, dimana semakin tinggi resolusi yang digunakan maka semakin banyak piksel dan semakin bagus kualitas dari citra tersebut, begitu pula sebaliknya. Pada saat sistem dapat mengidentifikasi citra objek maka sistem juga dapat menampilkan informasi buku yang sesuai.

Tabel 5. Data Pengujian Tingkat Resolusi Citra

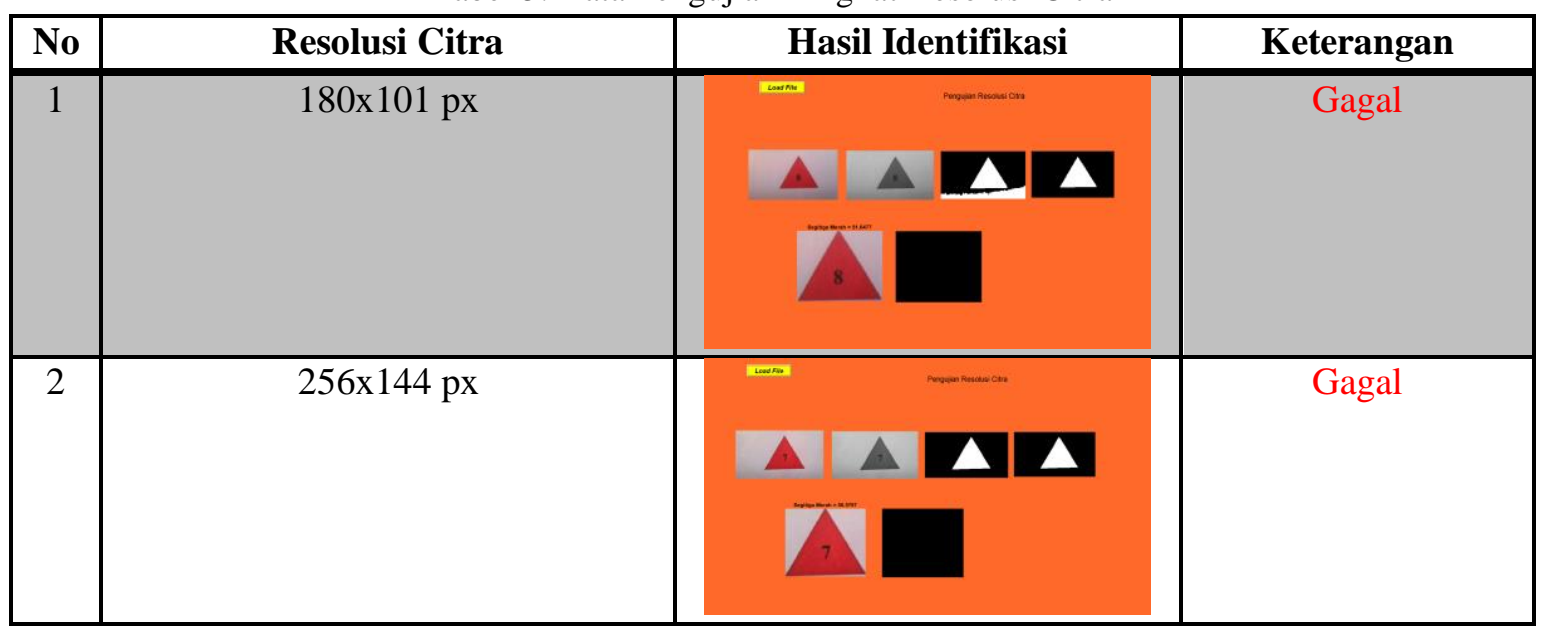




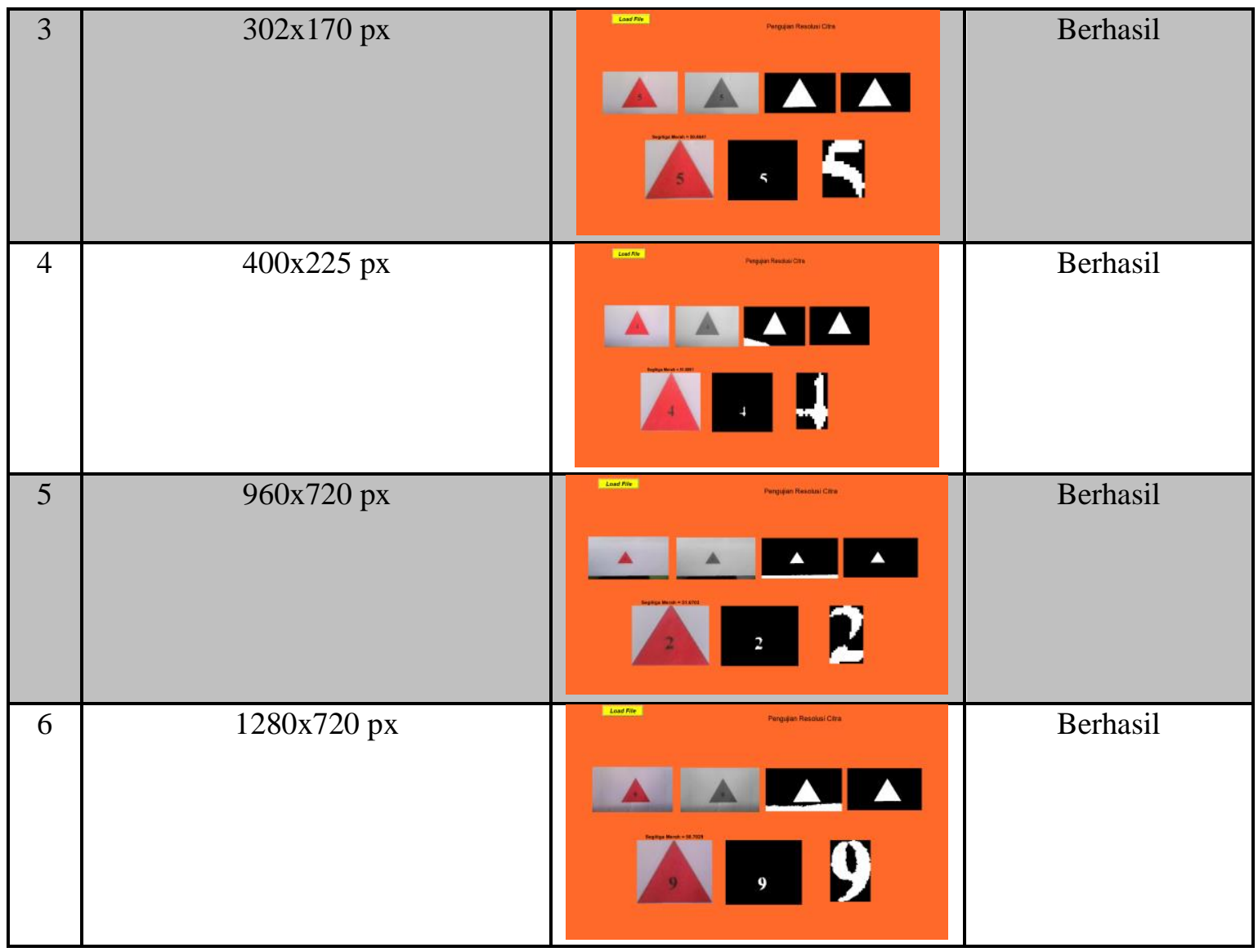

\subsection{Pengujian Font dan Ukuran Angka}

Pengujian yang dilakukan untuk melihat performansi sistem dalam mengidentifikasi saat angka pada citra objek diubah jenis font dan ukuran. Pengambilan data menggunakan kondisi ideal sesuai hasil pengujian pada sub bab sebelumnya. Jenis font yang digunakan adalah Calibri dengan ukuran dua belas. Pada Tabel 6 menyajikan data pengujian yang diambil sebanyak tiga kali dan hasil akhir menunjukkan bahwa sistem tidak dapat mengidentifikasi citra objek terutama bagian angka. Hal ini disebabkan format angka citra objek tidak sama dengan yang ada pada template, dimana seperti diketahui bahwa untuk identifikasi angka menggunakan template matching dan template yang dijadikan acuan yaitu font Times New Roman ukuran 12. Saat sistem tidak gagal melakukan identifikasi citra objek maka secara otomatis sistem juga tidak dapat menampilkan informasi buku.

Tabel 6. Data Pengujian Font dan Ukuran Angka

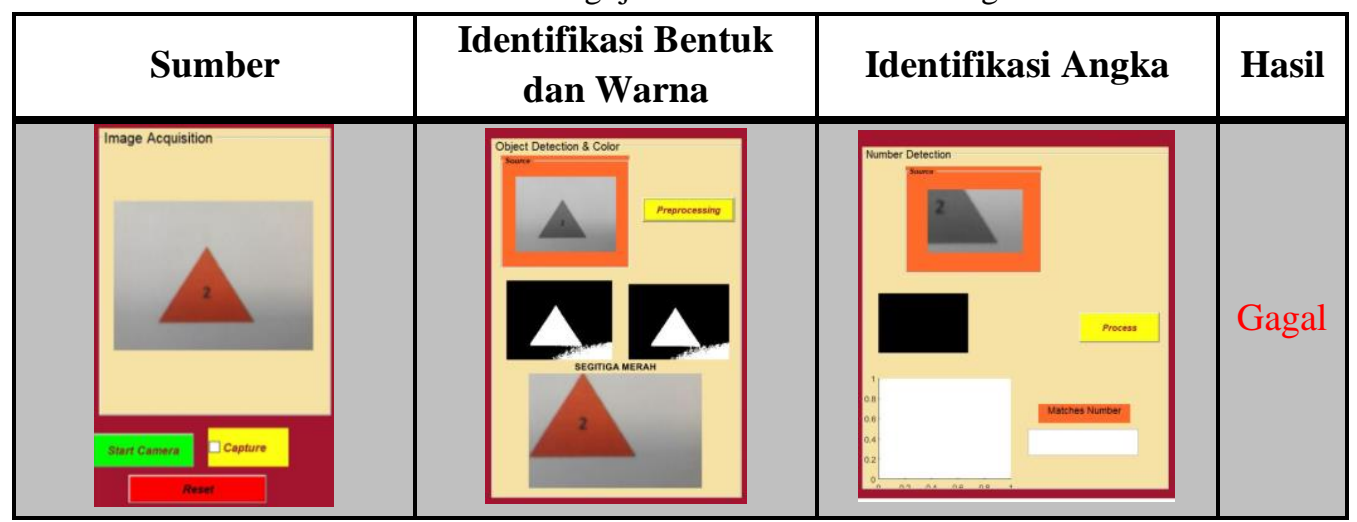




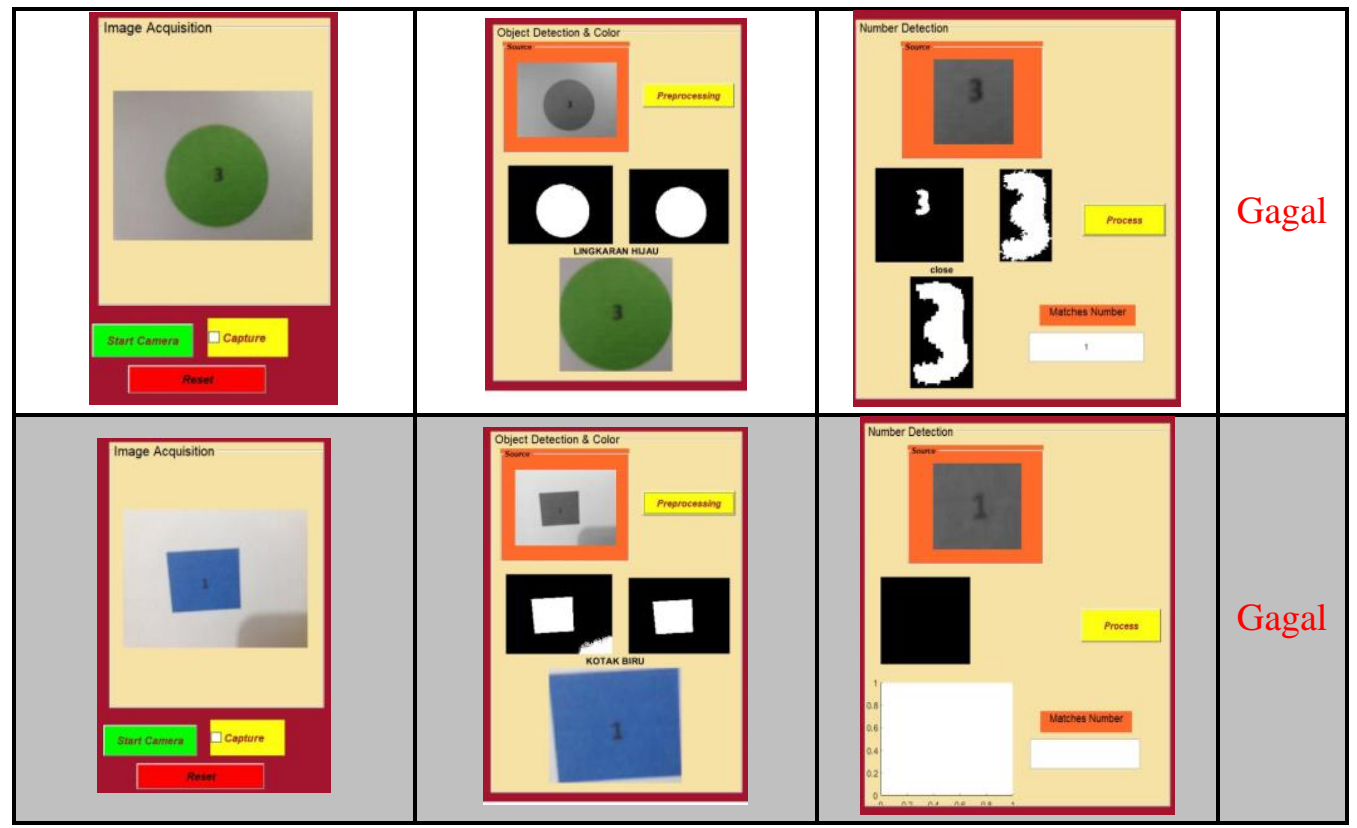

\section{KESIMPULAN}

Pembuatan aplikasi pembacaan objek untuk identifikasi buku berbasis pengolahan citra telah berhasil dilakukan. Sistem dapat mengidentifikasi bentuk, warna, dan angka citra objek. Identifikasi bentuk dan warna menggunakan segmentasi citra, sedangkan identifikasi angka menggunakan template matching. Pada aplikasi ditunjukkan proses pengolahan citra untuk identifikasi bentuk, warna, dan angka. Jarak ideal antara buku dengan kamera adalah $5 \mathrm{~cm}$ dengan minimal intensitas cahaya 40 lx dan resolusi citra 302x170 px. Rata-rata waktu yang dibutuhkan mulai kamera mengambil citra sampai aplikasi menampilkan informasi buku adalah 0.56 detik. Sistem belum dapat mengakomodir citra objek yang ditambahkan noise dan format angka yang berbeda dengan template.

\section{DAFTAR PUSTAKA}

[1] K. B. B. Indonesia, "Pustaka." [Online]. Available: https://kbbi.web.id/pustaka. [Accessed: 10-Jan-2021].

[2] E. P. M. Putuasduki, "Pemanfaatan QR Code Pada Perpustakaan Untuk Pemeringkatan , Peminjaman, dan Pemeliharaan Buku," in e-Indonesia Initiatives (eII Forum) 2015, 2015, no. October.

[3] F. S. Mukti and Setyorini, "Perancangan Sistem Informasi Manajemen Taman Baca Masyarakat Berbasis QR-Code," in Seminar Nasional Fortei Regional 7, 2020, no. November, pp. 166-170.

[4] O. Sholeh, D. Sopiyan, V. Ristiandana, and A. Zaeni, "Aplikasi Pemanfaatan Barcode Untuk Transaksi Di Perpustakaan SMAN 18 Kabupaten Tangerang," in Seminar Nasional Sistem Informasi Indonesia, 2013, pp. 224-229.

[5] A. Sulistyowati, Y. S. Hariyani, and A. Novianti, "Perancangan Aplikasi Pembaca Warna dan Bentuk Berbasis Pengolahan Citra untuk Daftar Katalog Perpustakaan," e-Proceeding Appl. Sci., vol. 4, no. 3, pp. 2554-2566, 2018.

[6] A. Gunes, H. Kalkan, and E. Durmus, "Optimizing the Color-to-Grayscale Conversion for Image Classification,” Int. J. Signal Image Video Process., no. July, 2016.

[7] Z. Rahman, Y.-F. Pu, M. Aamir, and F. Ullah, "A Framework for Fast Automatic Image 
Jurnal Elektro Telekomunikasi Terapan Desember 2020

Cropping Based On Deep Saliency Map Detection and Gaussian Filter," Int. J. Comput. Appl., no. March, pp. 1-11, 2018.

[8] R. Munir, "Citra Biner," in Interpretasi dan Pengolahan Citra, 2019.

[9] X. Zheng, Q. Lei, R. Yao, Y. Gong, and Q. Yin, "Image Segmentation Based On Adaptive K -means Algorithm," EURASIP J. Image Video Process., pp. 1-10, 2018.

[10] K. Thakar, D. Kapadia, F. Natali, and J. Sarvaiya, "Implementation and Analysis of Template Matching for Image Registration on DevKit-8500D," Opt. - Int. J. Light Electron Opt., pp. $1-21,2016$. 